\title{
Overtube-guided endoscopic extraction of a rectal foreign body: lifting not only the embargo
}

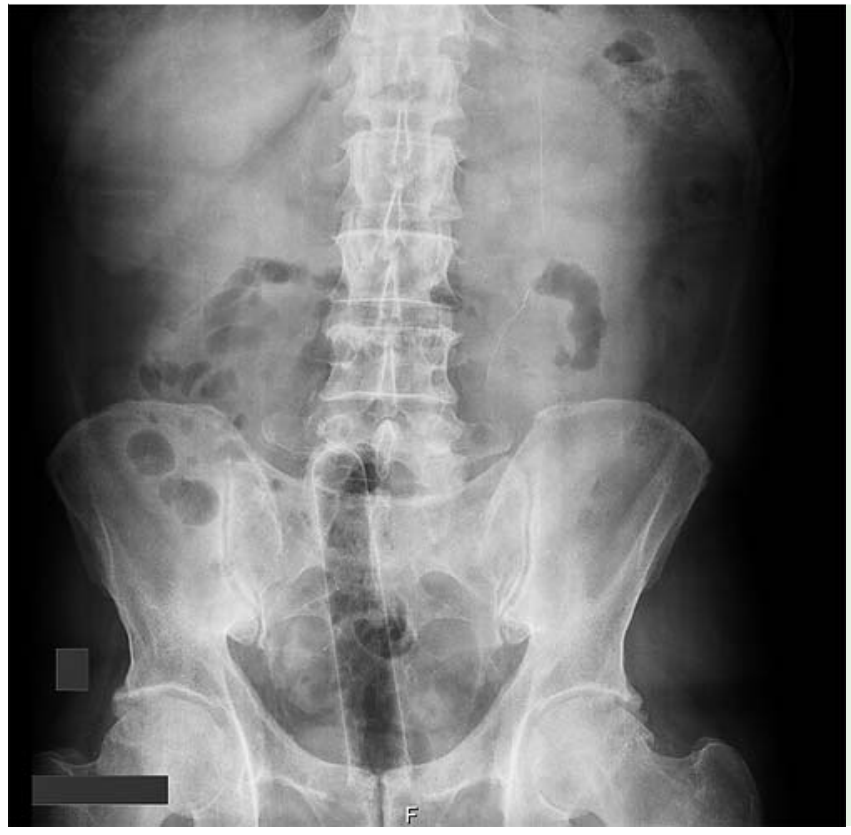

Fig. 1 Plain radiograph of the abdomen of a 65 -year-old man presenting to the emergency department shows a long, radiopaque, cylindrical foreign body in the rectum and sigmoid.
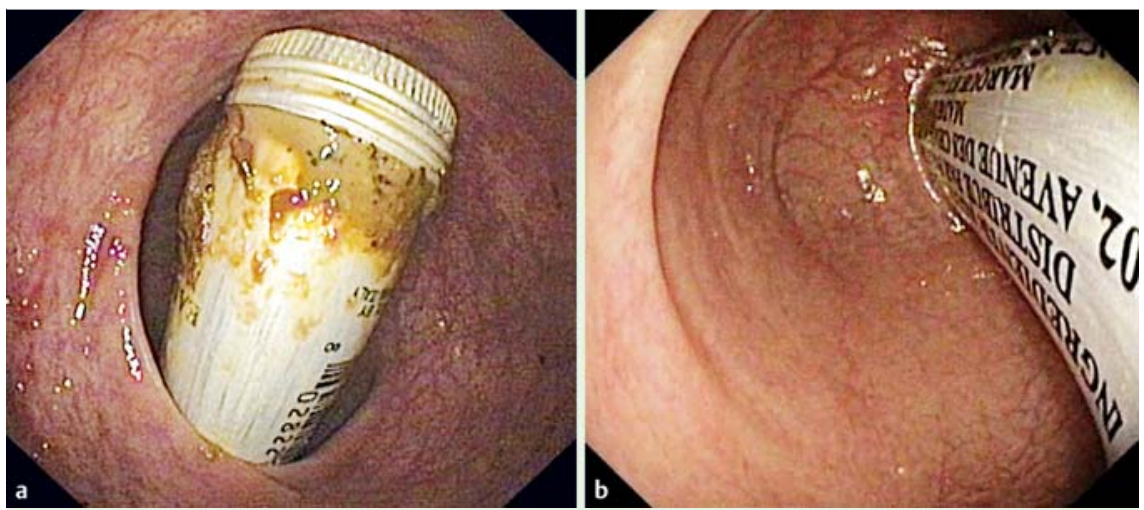

Fig. 2 Proctosigmoidoscopy revealing a cigar case: $\mathbf{a}$ in the rectum; $\mathbf{b}$ in the sigmoid.

A 65-year-old man presented to the emergency department with a foreign body in his rectum. He had inserted a Cuban cigar case into his anus approximately 9 hours before admission. The case had no sharp edges, and its cap was on.

The patient's abdomen was soft and not distended. Abdominal radiography showed a long, radiopaque, cylindrical foreign body in the rectum and sigmoid ( Fig. 1), with no signs of perforation. Proctosigmoidoscopy, performed without sedation, confirmed the presence of the object ( $\bullet$ Fig.2). Several attempts were made to remove it with a polypectomy snare, but the foreign body was very long and inflexible, so that it could not pass through the acute angle of the rectosigmoid junction.

An esophageal overtube was then introduced up to the proximal edge of the cylindrical case, reducing the angle of the rectosigmoid junction so that the distal tip of the case could be disimpacted ( $\bullet$ Video 1 ). With its distal tip fixed by a polypectomy snare, the foreign body was moved to the distal rectum and finally removed with manual assistance ( Fig.3). Afterward, the endoscope was removed, and no complication followed the procedure. The patient was asymptomatic at discharge.

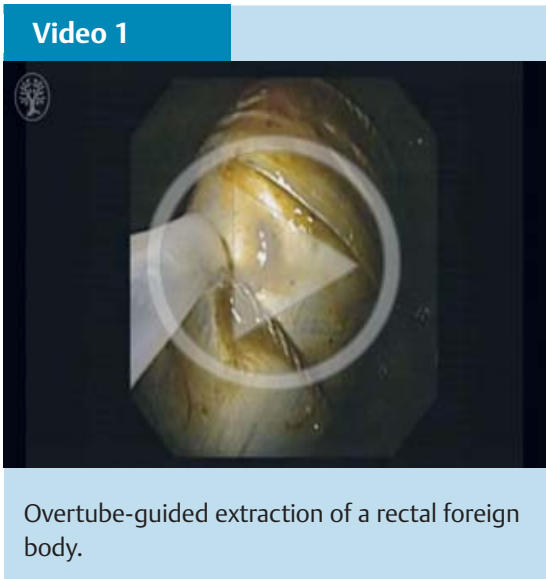

Retained rectal foreign bodies are not uncommon and often present a management dilemma [1,2]. Frequently, hospital admission is delayed until after several efforts have been made to remove the object at home [1]. Extraction can be difficult, and severe complications may occur [1].

Low-lying foreign bodies are usually palpable on digital rectal examination and can often be removed manually [3]. High-lying foreign bodies are located proximally to the rectosigmoid junction, and proctosigmoidoscopy is required for removal $[3,4]$. Surgery should be reserved for unstable patients, those with perforation, and those in whom transanal attempts at removal have failed [1].

To the best of our knowledge, no previous cases in which this technique was used have been described. The use of an overtube can straighten the colorectum, facilitating the removal of a rectal foreign body.

Endoscopy_UCTN_Code_TTT_1AQ_2AH

Competing interests: None

\section{Marco Silva, Andreia Albuquerque, Armando Ribeiro, Hélder Cardoso, Guilherme Macedo}

Gastroenterology Department, Centro Hospitalar São João, Faculty of Medicine of the University of Porto, Porto, Portugal 


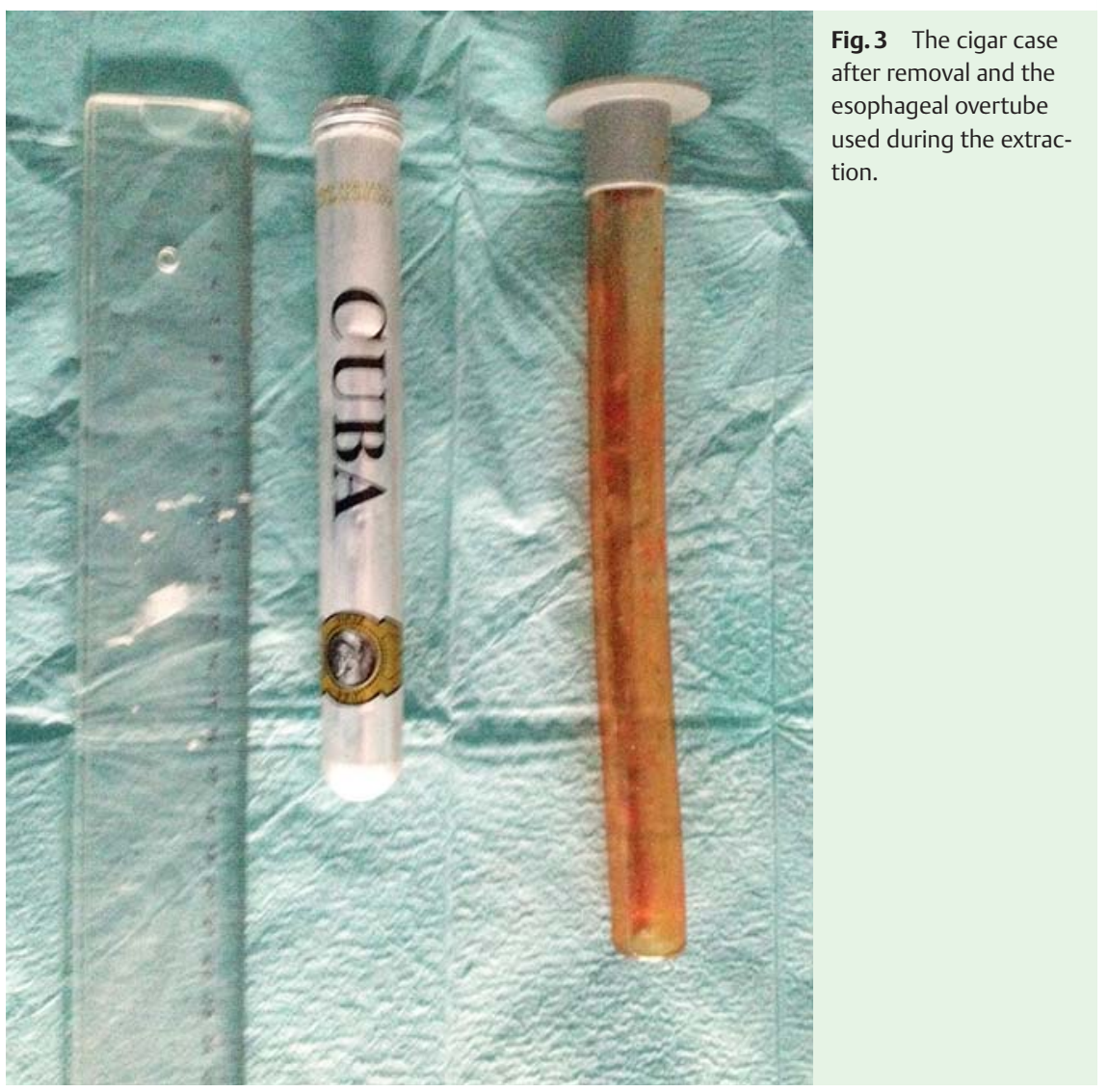

\section{References}

1 Coskun A, Erkan N, Yakan S et al. Management of rectal foreign bodies. World J Emerg Surg 2013; 8: 11

2 Cologne KG, Ault GT. Rectal foreign bodies: what is the current standard? Clin Colon Rectal Surg 2012; 25: 214-218

3 Anderson KL, Dean AJ. Foreign bodies in the gastrointestinal tract and anorectal emergencies. Emerg Med Clin North Am 2011; 29: 369-400

4 Lyons MF, Tsuchida AM. Foreign bodies of the gastrointestinal tract. Med Clin North Am 1993; 77: 1101 - 1114

\section{Bibliography}

DOI http://dx.doi.org/

10.1055/s-0034-1393392

Endoscopy 2015; 47: E563-E564

(c) Georg Thieme Verlag KG

Stuttgart · New York

ISSN 0013-726X

\section{Corresponding author}

\section{Marco Silva, MD}

Gastroenterology Department

Centro Hospitalar São João

Alameda Professor Hernâni Monteiro 4200-319 Porto

Portugal

Fax: +351-225-025-766

marcocostasilva87@gmail.com 